\title{
Sorting out Downside Beta
}

\section{Thierry Post, Pim van Vliet, and Simon Lansdorp}

\begin{tabular}{|l|l|}
\hline \multicolumn{2}{|l|}{ ERIM REPORT SERIES RESEARCH IN MANAGEMENT } \\
\hline ERIM Report Series reference number & ERS-2009-006-F\&A \\
\hline Publication & February 2009 \\
\hline Number of pages & 28 \\
\hline Persistent paper URL & http://hdl.handle.net/1765/14843 \\
\hline Email address corresponding author & wvanvliet@ese.eur.nl \\
\hline Address & Erasmus Research Institute of Management (ERIM) \\
& RSM Erasmus University / Erasmus School of Economics \\
& Erasmus Universiteit Rotterdam \\
& P.O.Box 1738 \\
& 3000 DR Rotterdam, The Netherlands \\
& Phone: + 31104081182 \\
& Fax: $\quad+31104089640$ \\
& Email: info@erim.eur.nl \\
& Internet: $\quad$ www.erim.eur.nl \\
\hline
\end{tabular}

Bibliographic data and classifications of all the ERIM reports are also available on the ERIM website: www.erim.eur.n 


\section{ERASMUS RESEARCH INSTITUTE OF MANAGEMENT}

\section{REPORT SERIES}

\section{RESEARCH IN MANAGEMENT}

\begin{tabular}{|l|l|}
\hline \multicolumn{2}{|l|}{ ABSTRACT AND KEYWORDS } \\
\hline Abstract & $\begin{array}{l}\text { Downside risk, when properly defined and estimated, helps to explain the cross-section of US } \\
\text { stock returns. Sorting stocks by a proper estimate of downside market beta leads to a } \\
\text { substantially larger cross-sectional spread in average returns than sorting on regular market } \\
\text { beta. This result arises despite the fact that downside beta is based on fewer return observations } \\
\text { and therefore is more difficult to estimate and predict. The explanatory power of downside risk } \\
\text { remains after controlling for other stock characteristics, including firm-level size, value and } \\
\text { momentum. }\end{array}$ \\
\hline Free Keywords & asset pricing, downside risk, semi-variance, lower partial moments \\
\hline Availability & $\begin{array}{l}\text { The ERIM Report Series is distributed through the following platforms: } \\
\text { Academic Repository at Erasmus University (DEAR), DEAR ERIM Series Portal } \\
\text { Social Science Research Network (SSRN), SSRN ERIM Series Webpage } \\
\text { Research Papers in Economics (REPEC), REPEC ERIM Series Webpage }\end{array}$ \\
\hline Classifications & $\begin{array}{l}\text { The electronic versions of the papers in the ERIM report Series contain bibliographic metadata } \\
\text { by the following classification systems: } \\
\text { Library of Congress Classification, (LCC) LCC Webpage } \\
\text { Journal of Economic Literature, (JEL), JEL Webpage } \\
\text { ACM Computing Classification System CCS Webpage } \\
\text { Inspec Classification scheme (ICS), ICS Webpage }\end{array}$ \\
\hline
\end{tabular}




\title{
Sorting out Downside Beta
}

\author{
THIERRY POST, PIM VAN VLIET AND SIMON LANSDORP*
}

\begin{abstract}
Downside risk, when properly defined and estimated, helps to explain the cross-section of US stock returns. Sorting stocks by a proper estimate of downside market beta leads to a substantially larger cross-sectional spread in average returns than sorting on regular market beta. This result arises despite the fact that downside beta is based on fewer return observations and therefore is more difficult to estimate and predict. The explanatory power of downside risk remains after controlling for other stock characteristics, including firm-level size, value and momentum.
\end{abstract}

February 2009

JEL: C22, C32, G11, G12

Keywords: Asset pricing, downside risk, semi-variance, lower partial moments

*Pim van Vliet is at Robeco Asset Management and Erasmus University Rotterdam, email: wvanvliet@ese.eur.nl tel: +31-102242579. Thierry Post is at Cass Business School and University of Wales at Bangor and Simon Lansdorp is at Erasmus University Rotterdam. We appreciate the suggestions made by Martijn van den Assem, Turan Bali, Guido Baltussen, Werner de Bondt, Stephen Brown, Haim Levy, Marc Schauten and Philippe Versijp. Financial support by Tinbergen Institute, Erasmus Research Institute of Management and Erasmus Center of Financial Research is gratefully acknowledged. 


\title{
Sorting out Downside Beta
}

\begin{abstract}
Downside risk, when properly defined and estimated, helps to explain the cross-section of US stock returns. Sorting stocks by a proper estimate of downside market beta leads to a substantially larger cross-sectional spread in average returns than sorting on regular market beta. This result arises despite the fact that downside beta is based on fewer return observations and therefore is more difficult to estimate and predict. The explanatory power of downside risk remains after controlling for other stock characteristics, including firm-level size, value and momentum.
\end{abstract}

A well-known objection against variance as a measure of investment risk is that it assigns the same weight to upward and downward deviations from the mean. The same argument also casts doubt on market beta as a measure for the systematic risk of individual stocks. For example, a stock that has gone up faster than others during market upswings and has gone down slower than others during market downswings, will be considered by most investors as a low-risk stock.

An appealing candidate to replace variance is semi-variance, already advocated by Markowitz (1959). Semi-variance measures the average squared downward deviation from a return threshold, and is also known as the secondorder lower-partial moment (LPM). Hogan and Warren (1974) and Bawa and Lindenberg (1977) developed a market equilibrium based on this risk measure. In their model, the regular market beta is replaced with a downside beta that emphasizes the co-movements of individual stocks with the market during market downturns as a measure of systematic downside risk.

Price, Price and Nantell (1982) show that the historical downside betas of US stocks systematically differ from the regular betas. Specifically, the regular beta underestimates the risk for low-beta stocks and overestimates the risk for high-beta stocks. This finding may help to explain why low-beta stocks appear systematically underpriced and high-beta stocks appear systematically overpriced in empirical tests of the mean-variance CAPM (see, for example, Black, Jensen and Scholes (1972), Fama and MacBeth (1973), Reinganum (1981), and Fama and French (1992).

Unfortunately, despite the intuitive and theoretical appeal of downside beta and the empirical problems of regular beta, the role of downside risk for the cross-section of stock returns remains an open question. Not withstanding some 
important contributions in this area, issues related to data and methodology of earlier studies do not allow for an unambiguous conclusion. An early study of the mean-semivariance equilibrium model by Jahankhani (1976) focuses on the relatively short sample period 1951-1969 that does not include the important bear markets of the 1930s, 1970s and 2000s. This may critically affect the conclusion that the model does not fare any better than the CAPM. Price, Price and Nantell (1982) demonstrate the divergence between regular beta and downside beta, but they do not analyze the cross-sectional explanatory power of downside beta. Harlow and Rao (1989) examine a generalization of the meansemivariance equilibrium model, based on general lower partial moments. Unfortunately, their regression-based asymmetric response model (ARM) generally does not estimate the lower-partial-moment beta, a problem that is discussed in the next section. Ang, Chen and Xing (2006) define downside beta as the standardized covariance during a falling market. Unfortunately, as discussed in the next section, this definition is not consistent with the theoretical meansemivariance framework, and, more worryingly, generally does not seem economically meaningful. Finally, some studies have focused on in-sample analysis and have not covered the estimation of downside beta from prior data and out-of-sample prediction of expected returns.

The purpose of this study is to provide a rigorous empirical analysis of the role of downside beta for the cross-section of stock returns. Using stock market data from 1926 to the present, we create stock portfolios based on past estimates of regular beta and various estimates of downside beta. Subsequently, we analyze the betas and means of these portfolios out-of-sample. We find that downside risk, when properly defined and estimated, drives stock prices. Sorting stocks by semivariance beta leads to an annual cross-sectional mean spread of 5.5\%, compared to $3.7 \%$ for sorting by regular beta. This result arises despite the fact that downside beta is based on fewer return observations and is more difficult to estimate and predict than regular beta. Semivariance beta also dominates regular beta after controlling for other stock characteristics, including firm-level size, value and momentum. Using the ARM regressions or covariance-based definition leads to markedly different results. The ARM results are very close to those obtained with the standard market beta and do not seem to reflect systematic downside risk. Using downside-covariance betas leads to more noisy estimates of systematic downside risk and a significant deterioration of the crosssectional mean spread.

The remainder of this study is structured as follows. Section I first discusses the various ways to define and estimate downside beta. We will introduce the downside beta that is consistent with the theoretical mean- 
semivariance model. In addition, we will show that the ARM regressions and covariance-based definition generally do not produce the semivariance beta. Both approaches tacitly assume that upside risk and downside risk are symmetric. Section II discusses our data and methodology. Next, Section III presents our results. Finally, Section IV summarizes our findings and gives some suggestions for further research.

\section{Measuring Downside Beta}

This section introduces semi-variance and the associated downside beta. It also introduces the asymmetric response model (ARM) beta and the downsidecovariance beta and derives the formal conditions under which these alternative betas equal the semivariance beta. A simple numerical example illustrates the differences between the various estimates of systematic downside risk.

\section{Semivariance Beta}

Semi-variance measures the average squared downward deviation from a return threshold:

$$
S V \equiv E\left[(R-k)^{2} \mid R \leq k\right]
$$

In this expression, $R$ is the investment return in excess of the riskless rate and $k$ is a return threshold that separates "losses" from "gains". This risk measure is also known as the second-order lower partial moment.

For nominal returns, plausible values for the threshold range from zero (the investor benchmarks against the initial value of her portfolio) to the average market return (the market portfolio is the benchmark). Hogan and Warren (1974) and Bawa and Lindenberg (1977) choose $k=0$ for their equilibrium model. Since the threshold is applied to excess returns, this choice boils down to using the riskless rate as the threshold for nominal returns. In this paper, we will adhere to this specification. Fortunately, the empirical results are very robust to the use of alternative plausible thresholds. In order to significantly change the empirical results, we need to select a threshold from the left tail or the right tail of the distribution. However, a threshold from the left tail generally excludes too many return observations to allow for accurate estimation for downside beta, and the beta no longer measures downside risk when the threshold is taken from the right tail. 
The equilibrium model of Hogan and Warren (1974) and Bawa and Lindenberg (1977) preserves all key characteristics of the CAPM, including the two-fund separation principle, efficiency of the market portfolio and the linear risk-return relationship. The key difference is that semi-variance replaces variance as the relevant portfolio risk measure. The following "semivariance beta" arises as the relevant measure of systematic risk for an individual stock (see, for example, Bawa and Lindenberg, 1977, p. 196, Eq. 5):

$$
\beta_{S V, i} \equiv \frac{E\left[R_{M} R_{i} \mid R_{M} \leq 0\right]}{E\left[R_{M}^{2} \mid R_{M} \leq 0\right]}
$$

The numerator of this expression is the second lower partial co-moment between the stock return $R_{i}$ and the market return $R_{M}$ and measures the comovements with the market during market downturns. This co-moment is standardized with the semi-variance of the market. The resulting beta measures the contribution of the evaluated stock to the semi-variance of the market portfolio, just like the regular beta measures the contribution to the variance of the market portfolio.

Since the semivariance beta is only based on market downswings, it is more difficult to estimate empirically than the regular beta. For example, the CRSP all-equity index, our proxy for the market, yielded a negative excess return in roughly $40 \%$ of the monthly observations in our sample from January 1926 to December 2007. This implies that estimation error needs to be taken into account when analyzing the explanatory power of downside risk and out-of-sample results are likely to look worse than in-sample results.

The following linear risk-return relationship applies in equilibrium:

$$
E\left[R_{i}\right]=\beta_{S V, i} E\left[R_{M}\right]
$$

It should be stressed that this relationship links the unconditional expected returns $E\left[R_{i}\right]$ and $E\left[R_{M}\right]$. The motivation for focusing on downside beta is that the sensitivity of stock returns to the market may change with the level of the market returns, leading to an asymmetric risk profile. Therefore, conditional versions of the risk-return relationship, such as $E\left[R_{i} \mid a \leq R_{M} \leq b\right]=\beta_{S V, i} E\left[R_{M} \mid a \leq R_{M} \leq b\right]$, generally do not apply. This insight will prove essential to understanding the differences between semivariance beta and other measures of downside beta. 
Asymmetric Response Model (ARM)

Regular betas are often computed by estimating "characteristic lines" using linear regression analysis. Harlow and Rao (1989) design a regression model to estimate the betas of a general lower-partial-moments equilibrium model. Unfortunately, this asymmetric response model (ARM) generally does not produce the correct lower-partial-moments betas.

Applying their model to the case of semi-variance and using our notation, Harlow and Rao (1989, Eq. 10) employ the following bivariate regression model to estimate their downside beta:

$$
R_{i}=\alpha_{A R M, i}+\beta_{A R M, i} X+\gamma_{A R M, i} Z+\varepsilon_{i}
$$

where $\quad X \equiv\left(R_{M} 1_{R_{M} \leq 0}+E\left[R_{M} \mid R_{M}>0\right] 1_{R_{M}>0}\right)$ and $Z \equiv\left(R_{M} 1_{R_{M}>0}-E\left[R_{M} \mid R_{M}>0\right] 1_{R_{M}>0}\right)$. In these regressors, $1_{R_{M} \leq 0}$ is a down-market dummy and $1_{R_{M}>0}$ is an up-market dummy. The expected values of these dummies are the probabilities of downs and ups: $E\left[1_{R_{M} \leq 0}\right]=\operatorname{Pr}\left[R_{M} \leq 0\right], E\left[1_{R_{M}>0}\right]=\operatorname{Pr}\left[R_{M}>0\right]$; the expected values of the regressors are simply $E[X]=E\left[R_{M}\right]$ and $E[Z]=0$.

Since $X$ and $Z$ are independent by construction, the ARM beta equals the univariate regression coefficient for $X$ :

$$
\begin{gathered}
\beta_{A R M, i}=\frac{E\left[X R_{i}\right]-E[X] E\left[R_{i}\right]}{E\left[X^{2}\right]-E[X]^{2}} \\
=\frac{E\left[R_{M} R_{i} \mid R_{M} \leq 0\right] \operatorname{Pr}\left[R_{M} \leq 0\right]+E\left[R_{M} \mid R_{M}>0\right] E\left[R_{i} \mid R_{M}>0\right] \operatorname{Pr}\left[R_{M}>0\right]-E\left[R_{M}\right] E\left[R_{i}\right]}{E\left[R_{M}^{2} \mid R_{M} \leq 0\right] \operatorname{Pr}\left[R_{M} \leq 0\right]+E\left[R_{M} \mid R_{M}>0\right]^{2} \operatorname{Pr}\left[R_{M}>0\right]-E\left[R_{M}\right]^{2}}
\end{gathered}
$$

In contrast to the semivariance beta, this expression includes several terms that are affected by the return values during market upswings. These terms enter because the ARM regressor takes a non-zero value during market upswings, that is, $X=E\left[R_{M} \mid R_{M}>0\right]$. This is a first indication that the ARM beta may not be a pure measure of downside risk, but rather mixes upside deviations and downside deviations.

To further investigate the relationship between the two betas, it is useful to consider the case where the betas are identical and in addition the meansemivariance model applies. In this case, we can substitute $\beta_{A R M, i}=\beta_{S V, i}$, $E\left[R_{M} R_{i} \mid R_{M} \leq 0\right]=\beta_{S V, i} E\left[R_{M}^{2} \mid R_{M} \leq 0\right] \quad$ (from Definition (2)) and the equilibrium condition (3) in the numerator of the right-hand side of (5), to find: 


$$
\begin{gathered}
\beta_{S V, i}=\frac{\beta_{S V, i} E\left[R_{M}^{2} \mid R_{M} \leq 0\right] \operatorname{Pr}\left[R_{M} \leq 0\right]+E\left[R_{M} \mid R_{M}>0\right] E\left[R_{i} \mid R_{M}>0\right] \operatorname{Pr}\left[R_{M}>0\right]-\beta_{S V, i} E\left[R_{M}\right]^{2}}{E\left[R_{M}^{2} \mid R_{M} \leq 0\right] \operatorname{Pr}\left[R_{M} \leq 0\right]+E\left[R_{M} \mid R_{M}>0\right]^{2} \operatorname{Pr}\left[R_{M}>0\right]-E\left[R_{M}\right]^{2}} \\
\Leftrightarrow 0=\frac{E\left[R_{M} \mid R_{M}>0\right]\left(E\left[R_{i} \mid R_{M}>0\right]-\beta_{S V, i} E\left[R_{M} \mid R_{M}>0\right]\right) \operatorname{Pr}\left[R_{M}>0\right]}{E\left[R_{M}^{2} \mid R_{M} \leq 0\right] \operatorname{Pr}\left[R_{M} \leq 0\right]+E\left[R_{M} \mid R_{M}>0\right]^{2} \operatorname{Pr}\left[R_{M}>0\right]-E\left[R_{M}\right]^{2}} \\
\Leftrightarrow E\left[R_{i} \mid R_{M}>0\right]=\beta_{S V, i} E\left[R_{M} \mid R_{M}>0\right]
\end{gathered}
$$

The final equation follows from the observation that the denominator and the terms $E\left[R_{M} \mid R_{M}>0\right]$ and $\operatorname{Pr}\left[R_{M}>0\right]$ from the numerator of the second equation are strictly positive. Hence, the term $\left(E\left[R_{i} \mid R_{M}>0\right]-\beta_{S V, i} E\left[R_{M} \mid R_{M}>0\right]\right)$ from the numerator equals zero.

Equation (6) basically assumes that the unconditional risk-return relationship (3) also applies during market upswings. In this case, the upswing terms in Equation (5) can be shown to cancel out and do not affect the definition of downside beta. Unfortunately, this condition generally is violated if the stock has a different market beta for losses than for gains. Hence, the ARM beta $\beta_{A R M, i}$ generally differs from the semivariance beta $\beta_{S V, i}$.

The ARM beta not only reflects co-movements during market downswings, but also co-movements during market upswings, because the ARM regressor equals the conditional average market return $X=E\left[R_{M} \mid R_{M}>0\right]$ during upswings. The ARM beta will therefore be higher if the stock yields higher returns during market upswings. Indeed, the ARM regressor generally is highly correlated with the market return and the ARM beta is highly correlated with the regular market beta. The numerical example at the end of this section and the results in the empirical section further illustrate this point.

\section{Downside Covariance (DC) Beta}

Ang, Chen and Xing (2006, Eq. 5) interpret downside beta as the standardized covariance during a falling market: ${ }^{1}$

$$
\beta_{D C, i} \equiv \frac{\operatorname{Cov}\left[R_{i}, R_{M} \mid R_{M} \leq 0\right]}{\operatorname{Var}\left[R_{M} \mid R_{M} \leq 0\right]}
$$

\footnotetext{
1 Ang, Chen and Xing (2006) use the mean excess market return $\left(E\left[R_{M}\right]\right)$ rather than zero as the threshold for excess returns. Our arguments apply with equal strength for every target rate of return. Furthermore, the empirical effect of replacing the riskless rate with the mean market return typically is very small.
} 


$$
=\frac{E\left[R_{M} R_{i} \mid R_{M} \leq 0\right]-E\left[R_{M} \mid R_{M} \leq 0\right] E\left[R_{i} \mid R_{M} \leq 0\right]}{E\left[R_{M}^{2} \mid R_{M} \leq 0\right]-E\left[R_{M} \mid R_{M} \leq 0\right]^{2}}
$$

While the definition of semivariance beta is based on a second-order lower partial moment, this definition is based a conditional measure of variance. This means that returns during down markets are computed in deviation of the average return during down markets, and that the central tendency of losses plays no role in the definition of risk. This property is not consistent with the criterion of monotonicity for coherent risk measures (see, for example, Artzner et al., 1999); lowering the mean return during market losses increases the value of coherent risk measures, but it does not affect downside variance. Related to this, a portfolio model that balances mean return and downside variance would not be consistent with nonsatiation and risk aversion, two basic criteria for investor preferences. In addition, the implied pricing kernel of an equilibrium model that balances mean return against downside-covariance beta would not always be positive and decreasing, contrary to what finance textbooks require.

The following derivation yields the conditions under which the conditionalcovariance and semivariance definitions are equivalent:

$$
\begin{gathered}
\beta_{S V, i}=\beta_{D C, i} \\
\Leftrightarrow \frac{E\left[R_{M} R_{i} \mid R_{M} \leq 0\right]}{E\left[R_{M}^{2} \mid R_{M} \leq 0\right]}=\frac{E\left[R_{M} R_{i} \mid R_{M} \leq 0\right]-E\left[R_{M} \mid R_{M} \leq 0\right] E\left[R_{i} \mid R_{M} \leq 0\right]}{E\left[R_{M}^{2} \mid R_{M} \leq 0\right]-E\left[R_{M} \mid R_{M} \leq 0\right]^{2}} \\
\Leftrightarrow E\left[R_{M} R_{i} \mid R_{M} \leq 0\right] E\left[R_{M} \mid R_{M} \leq 0\right]=E\left[R_{M}^{2} \mid R_{M} \leq 0\right] E\left[R_{i} \mid R_{M} \leq 0\right] \\
\Leftrightarrow E\left[R_{i} \mid R_{M} \leq 0\right]=\frac{E\left[R_{M} R_{i} \mid R_{M} \leq 0\right]}{E\left[R_{M}^{2} \mid R_{M} \leq 0\right]} E\left[R_{M} \mid R_{M} \leq 0\right] \\
\Leftrightarrow E\left[R_{i} \mid R_{M} \leq 0\right]=\beta_{S V, i} E\left[R_{M} \mid R_{M} \leq 0\right]
\end{gathered}
$$

Like Equation (6), this equation basically is a conditional version of the unconditional cross-sectional relationship (3). The relationship is now assumed to apply also during market downturns. ${ }^{2}$ In this case, the above problem of ignoring

${ }^{2}$ Equation (6) and (8) are equivalent under the mean-semivariance equilibrium condition (3), because $E[R]=E\left[R \mid R_{M} \leq 0\right] \operatorname{Pr}\left[R_{M} \leq 0\right]+E\left[R \mid R_{M}>0\right] \operatorname{Pr}\left[R_{M}>0\right]$. However, Equation (8) is derived without Equation (3) and is generally not equivalent to Equation (6). 
the central tendency of losses indeed does not affect the definition of risk. Unfortunately, the conditional relationship generally does not hold when a stock has an asymmetric risk profile. Consequently, the downside-covariance beta $\beta_{D C, i}$ generally differs from the semivariance beta $\beta_{S V, i}$.

\section{Numerical example}

The differences between the three downside betas can be demonstrated by means of a simple example with a market index and an at-the-money call option on the market index. This setup represents for example investors who consider writing covered call options to reduce downside risk. For simplicity, we consider only four states-of-the-world of equal probability and assume that the riskless rate is zero. The returns are as follows:

\begin{tabular}{cccc}
\hline State & Prob. & $\begin{array}{c}\text { AM Call } \\
\text { Option } \\
\left(R_{i}\right)\end{array}$ & $\begin{array}{c}\text { Market } \\
\text { Index } \\
\left(R_{M}\right)\end{array}$ \\
\hline 1 & $25 \%$ & $-100 \%$ & $-15 \%$ \\
2 & $25 \%$ & $-100 \%$ & $-5 \%$ \\
3 & $25 \%$ & $+110 \%$ & $+15 \%$ \\
4 & $25 \%$ & $+250 \%$ & $+25 \%$ \\
\hline
\end{tabular}

The following table is helpful for computing the various betas:

\begin{tabular}{cccccccccc}
\hline State & Prob. & $R_{i}$ & $R_{M}$ & $X$ & $R_{i}^{2}$ & $R_{M}^{2}$ & $X^{2}$ & $R_{i} R_{M}$ & $R_{i} X$ \\
\hline 1 & $25 \%$ & -100 & -15 & -15 & 10,000 & 225 & 225 & 1,500 & 1,500 \\
2 & $25 \%$ & -100 & -5 & -5 & 10,000 & 25 & 25 & 500 & 500 \\
3 & $25 \%$ & 110 & 15 & 20 & 12,100 & 225 & 400 & 1,650 & 2,200 \\
4 & $25 \%$ & 250 & 25 & 20 & 62,500 & 625 & 400 & 6,250 & 5,000 \\
& & & & & & & & & \\
$E[\cdot]$ & & 40 & 5 & 5 & 23,650 & 275 & 262.5 & 2,475 & 2,300 \\
$E\left[\cdot \mid R_{M} \leq 0\right]$ & & -100 & -10 & -10 & 10,000 & 125 & 125 & 1,000 & 1,000 \\
$E\left[\cdot \mid R_{M}>0\right]$ & & 180 & 20 & 20 & 37,300 & 425 & 400 & 3,950 & 3,600 \\
\hline
\end{tabular}

The regular market beta in this case amounts to

$$
\beta_{R e g, i}=\frac{E\left[R_{i} R_{M}\right]-E\left[R_{i}\right] E\left[R_{M}\right]}{E\left[R_{M}^{2}\right]-E\left[R_{M}\right]^{2}}=\frac{2,475-40 \cdot 5}{275-5^{2}}=9.1
$$

This value is higher than the regular beta of a typical stock, because the call option involves more extreme negative and positive returns than a typical stock. 
The effect of including a call option in the portfolio is however mitigated by the value of the call option being only a fraction of that of the underlying index.

Since the call option is more sensitive to the market index when the market index goes up than when it goes down, we may expect the downside betas to give lower values. Indeed, the semivariance beta in this case takes the following value:

$$
\beta_{S V, i}=\frac{E\left[R_{i} R_{M} \mid R_{M} \leq 0\right]}{E\left[R_{M}^{2} \mid R_{M} \leq 0\right]}=\frac{1,000}{125}=8.0
$$

Thus, buying a dollar worth of call options adds eight times as much downside risk as investing a dollar in the market index. Conversely, writing a dollar worth of call options offsets the downside risk of eight dollars invested in the market index.

This example is constructed to be consistent with the mean-semivariance equilibrium model, that is, to obey the unconditional equality (3). However, the conditional equality (6) does not apply, because the call option has an asymmetric risk profile. Indeed, the ARM beta differs from the semivariance beta:

$$
\beta_{A R M, i}=\frac{E\left[R_{i} X\right]-E\left[R_{i}\right] E[X]}{E\left[X^{2}\right]-E[X]^{2}}=\frac{2,300-40 \cdot 5}{262.5-5^{2}}=8.8
$$

This value is close to that of the regular market beta. This is not surprising given that the correlation between the ARM regressor and the market return is $97.5 \%$ in this example.

The asymmetric risk profile of the call option also implies that the conditional equality (8) is violated. Hence, the conditional-covariance beta also differs from the semivariance beta:

$$
\beta_{D C, i}=\frac{E\left[R_{i} R_{M} \mid R_{M} \leq 0\right]-E\left[R_{i} \mid R_{M} \leq 0\right] E\left[R_{M} \mid R_{M \leq 0}\right]}{E\left[R_{M}^{2} \mid R_{M} \leq 0\right]-E\left[R_{M} \mid R_{M} \leq 0\right]^{2}}=\frac{1,000-(-100) \cdot(-10)}{125-(-10)^{2}}=0.0
$$

The value of zero suggests that a long position in the call option would reduce downside risk. However, while the call option reduces the uncertainty about the magnitude of possible losses (which is always -100\%), it does not reduce the probability of those losses and clearly increases the magnitude of the losses. 


\section{Data}

In our empirical analysis, we use monthly stock returns (including dividends and capital gains) from the Center for Research in Security Prices (CRSP) at the University of Chicago. The CRSP total return index is a value-weighted average of all US stocks included in this study. The one-month US Treasury bill is obtained from Ibbotson. We subtract the risk-free rate from nominal returns to obtain excess returns. To control for the book-to-market effect prior to 1963, we use the high-minus-low (HML) hedge portfolio from Kenneth French' data library. ${ }^{3}$

We select ordinary common US stocks listed on the New York Stock Exchange (NYSE), American Stock Exchange (AMEX) and Nasdaq markets. We exclude ADRs, REITs, closed-end-funds, units of beneficial interest, and foreign stocks. Hence, we only include stocks that have a CRSP share type code of 10 or 11. We require a stock to have (1) 60 months of data available (for beta estimation) and (2) information about market capitalization (defined as price times the number of outstanding shares) at formation date. Except for momentum (monthly rebalancing), portfolio formation takes place at December of each year. For example, to be included at December 1930 a stock must have trading information since January 1926 and a positive market capitalization for December 1930. A stock is excluded from the analysis if price information is no longer available. In that case, the delisting return or partial monthly return provided by CRSP is used as the last return observation.

When analyzing risk, it is particularly important to include periods during which investment risks are high and investors are sensitive to risk. In this respect, the failure of the mean-semivariance model to improve upon the meanvariance model in the analysis of Jahankhani (1976) is presumably caused by the focus on a sample period (1951-1969) that excludes the important bear markets of the 1930s, 1970s and 2000s. Nowadays, empirical researchers often confine themselves to the post-1963 period to avoid biases associated with the Compustat database. Nevertheless, since the revisions of 1999, the CRSP database is free of delisting bias and survivorship bias for the total 1926-2007 period. Therefore, when only CRSP data are used (without Compustat requirements) there is no reason to exclude the pre-1963 period. In fact, the early period seems particularly useful because it includes the bear market of the 1930s. This study will use the entire sample period of the 2007 CRSP database: January 1926 - December 2007.

\footnotetext{
${ }^{3}$ Kenneth French: http://mba.tuck.dartmouth.edu/pages/faculty/ken.french/data_library.html.
} 
Furthermore, we analyze the role of downside risk in four historical subsamples of 19 and 20 years, 1931-1949, 1950-1969, 1970-1988 and 1989-2007.

Rather than analyzing all individual stocks, empirical studies generally evaluate a small set of benchmark portfolios formed from the individual stocks. This reduces the computational burden of having to analyze thousands of individual stocks and also allows the researcher to control for particular stock characteristics and for changes of those characteristics (by periodically rebalancing the portfolios). The main part of our analysis focuses on benchmark portfolios that are based on regular market beta and downside market beta. If the mean-variance CAPM applies and regular beta drives stock prices, then sorting on other stock characteristics may lead to a lack of variation in means and erroneous rejections of the mean-variance CAPM. Similarly, if the meansemivariance CAPM applies, then sorting stocks on downside beta maximizes the mean spread and minimizes the probability of erroneous rejections of the meansemivariance CAPM.

At the end of December of each year, all stocks that fulfill our data requirements are sorted based on beta and grouped into ten decile portfolios consisting of an equal number of stocks. The sorting starts in December 1930, 60 months after the beginning of the CRSP files, because 60 months of prior data are needed for estimating the betas of the individual stocks when sorting on beta. The results are not affected by the sorting frequency. When sorting takes place on a monthly basis (instead of in December of each year), we find similar portfolio characteristics and test results.

Next, for each portfolio, value-weighted returns are calculated for the following 12 months. Using equal weighted returns would strengthen the case for using downside risk, because the differences between regular beta and downside beta are most pronounced for small cap stocks. Still, we prefer value-weighted returns to equal-weighted returns, because equal-weighted returns require continuous portfolio updating, which in practice involves high transaction costs. By contrast, value-weighted returns closely resemble a buy-and-hold strategy with relatively low transaction costs. When a stock is delisted or removed from the database after formation date, the portfolio return is calculated as the average for the remaining stocks in the portfolio during the holding period.

In practice, regular beta and the several downside beta definitions are highly correlated. To disentangle the effect of the different (downside) risk measures, we apply a double-sorting routine. We sort stocks first into quintile portfolios based on regular-beta and then subdivide each regular-beta quintile into five portfolios based on three definitions of downside beta: semivariance beta, ARM beta, and downside covariance beta. These downside betas are defined 
in equations (2), (5), and (7) respectively. In addition, we also control for downside risk by first sorting on the three definitions of downside beta and subsequently by sorting on the other (downside) betas. In sum, we generate 12 sets of double-sorted beta portfolios.

Similarly, we use double-sorted portfolios to separate the effect of regular beta and downside beta from the effect of other sorting variables that are known to be relevant for explaining the cross-section of risk and return: co-skewness, volatility, idiosyncratic volatility, size, value, reversal and momentum. Prior to 1963, we solely rely on the CRSP database and use HML-betas to classify a stock as a growth or value without direct use of accounting multiples from Compustat. HML beta is measured relative to the Fama and French high-minus-low hedge portfolio over a 60-month period. The size control uses NYSE quintile market capitalization breakpoints which results in a larger number of stocks in the low size quintiles. For momentum and reversal, we use the Fama and French (1996) definitions 12-1 and 60-12 month stock return. Total volatility and co-skewness are estimated using a 60-month period. Idiosyncratic volatility is estimated over a 60-month period using the Fama-French three factor model. We also control for all of these cross-sectional effects simultaneously, using Fama \& MacBeth (1973) type regressions. The sample for these regressions, which contain stock characteristics such as Size and Book-to-Market (BtM), starts in January 1963.

\section{Results}

\section{A. Beta-sorted decile portfolios}

Panel A of Table I shows the results for the portfolios based on regular beta. The mean return ranges from 60 to 91 basis points per month, an annual return spread of $3.7 \%$. The regular beta ranges from 0.66 for the bottom decile to 1.76 for the top decile, a spread of 1.10. Given that the annualized market risk premium was $8.0 \%$ during this sample period, these numbers are difficult to reconcile with the idea that market beta is the relevant risk measure.

Panel B shows what happens if we sort on semivariance beta instead of regular beta. The mean return ranges from 56 to 102 basis points per month, an annual return spread of $5.5 \%$. Recall that semivariance beta uses only a fraction of the monthly return observations and hence is more difficult to estimate than regular beta. Indeed, the relevant beta spread narrows to 0.98 . This number is not only lower than the regular-beta spread of 1.10 in Panel A, but also lower than the semivariance-beta spread of 1.06 in Panel A. The strong increase of the 
mean spread, suggests that semivariance beta, despite the estimation problems, is a more relevant measure of systematic risk than regular beta.

The results in Panel $\mathrm{C}$ are based on the ARM beta. As discussed above, the ARM beta generally deviates from the semivariance beta and is more likely to resemble the regular beta. Indeed, the correlation between the ARM beta and semivariance beta of individual stocks is $85 \%$ in our sample, while the correlation with regular beta is $94 \%$. Not surprisingly, the results in panel $\mathrm{C}$ are very similar to those in Panel A, with an annualized mean spread of $4.0 \%$ and an ARM beta spread of 1.05. These results illustrate that the ARM beta basically picks up systematic upside risk in addition to systematic downside risk.

Finally, Panel D is based on the downside-covariance beta. The mean return ranges from 66 to 89 basis points per month, an annualized spread of only $2.8 \%$. The relevant beta ranges from 0.88 to 1.58 , a spread of 0.69 . These results illustrate that the downside-covariance beta of stocks generally differs substantially from the semivariance beta. As discussed above, the divergence between the two downside betas arises because downside-covariance beta is invariant to the central tendency of losses. In addition, the low mean spread suggests that the downside-covariance beta does not capture priced downside risk.

\section{[Insert Table I about here]}

\section{B. Disentangling the competing betas}

The above results for beta-sorted portfolios clearly plead in favor of the semivariance beta. Still, the various betas are highly correlated, possibly obscuring the differences between them. To disentangle the effect of the various risk measures, Table II shows the results for the double-sorted portfolios. The results further support the conclusion that downside beta is more relevant to investors than regular beta and that downside beta is best measured using the semivariance definition.

Panel A shows the results for sorting stocks based on a downside beta measure after controlling for regular beta; every quintile now has the same distribution in terms of regular beta. Interestingly, after controlling for regular beta, the semivariance beta still yields a mean spread of 19 basis points per month and a beta spread of 0.20 , suggesting that it captures substantial priced risk that is not captured by regular beta. By contrast, the ARM model and downside-covariance model yield mean spreads of only 7 basis points. 
Panel B shows the results after first controlling for semivariance beta. The regular beta now yields a beta spread of 0.31. Since regular beta accounts for upside risk in addition to downside risk, and return distributions generally are not symmetric, it is not surprising that regular beta captures risk beyond semivariance beta. The interesting thing however is that the upside risk seems not priced by investors, witness the small mean spread of the regular-beta portfolios. In fact, the highest-regular-beta quintile actually earns five basis points less on average than the lowest-regular-beta quintile. Very similar results are found for the ARM regression methodology, which seems to unintentionally capture upside risk in addition to downside risk. The downside-covariance beta yields a zero mean spread, suggesting that it does not capture any priced downside risk beyond semivariance. In addition, the beta spread is only 2 basis points per month. These results suggest that downside-covariance beta essentially is a noisy proxy for the semivariance beta and does not capture additional downside risk, let alone priced downside risk.

Panel $\mathrm{C}$ shows the results after first sorting on the ARM betas. The results are very similar to those obtained after first sorting on regular beta. The semivariance beta yields a mean spread of 18 basis points per month and a beta spread of 0.15. By contrast, the regular beta and downside-covariance beta yield mean spreads of only 5 and 6 basis points, respectively. The close similarity between the results in panels $\mathrm{A}$ and $\mathrm{C}$ further illustrates that the ARM beta basically picks up systematic upside risk in addition to systematic downside risk.

Finally, Panel D shows what happens if we first sort stocks based on their downside-covariance beta. Interestingly, all three other betas (regular betas, semivariance beta and ARM beta) now yield very large beta spreads of 0.50 to 0.62 , suggesting that they capture substantial systematic risk beyond downside covariance. The semivariance beta in this case yields a mean spread of 21 basis points per month, compared with nine and ten basis points for regular beta and ARM beta. This further supports the notion that semivariance beta captures priced downside risk that is not captured by the other systematic risk measures.

[Insert Table II about here]

\section{Controlling for other stock characteristics}

It is well-known that stock characteristics such as firm-level size, value and momentum are correlated with average return and risk. To avoid wrongly attributing a mean spread to a beta spread, it is useful to control for other stock characteristics. 
Table III summarizes our results after correcting for a list of stock characteristics that are commonly used in the empirical asset pricing literature. For the sake of brevity, the table now includes only semivariance beta as the relevant measure of downside beta, and excludes ARM beta and covariance beta, which are both highly dominated by semivariance beta. The corrections generally change the mean spreads and beta spreads. However, the effect is similar for regular beta and downside beta or even strengthens the case for downside beta. For every stock characteristic, we see the same pattern. Sorting on semivariance beta leads to a larger mean spread, despite a smaller beta spread.

The mean spreads are lowest after controlling for variance. Variance is highly positively correlated with both regular beta and downside beta and correcting for it substantially reduced the flexibility for finding large beta spreads. The mean spread for regular-beta quintiles is zero. For semivariance beta, 14 basis points per month remain.

By contrast, the mean spreads are highest after controlling for HML exposure. Growth stocks tend to have relatively high betas and value stocks tend to have low betas. Hence, the value risk premium tends to artificially raise the returns of low-beta stocks and lower the return of high-beta stocks. Correcting for HML exposures therefore increases the mean spread.

Overall, the results suggest that the differences between regular beta and downside beta do not pick up omitted stock characteristics. This further supports the conclusion that downside beta, when properly defined and estimated, is relevant for understanding stock returns.

\section{[Insert Table III about here]}

\section{Fama-MacBeth regressions}

The analysis of single-sorted and double-sorted portfolios allows us to maximize the spread in the betas and to disentangle the effects of the competing betas. Unfortunately, this approach is too crude to correct for more than one stock characteristic at the time. The multivariate regression methodology of Fama and MacBeth (1973) can perform multiple corrections simultaneously. Table IV shows the results of applying this methodology to our data set. The results confirm the above results: the semivariance beta dominates the coefficients for the other betas, in terms of both economic significance and statistical significance.

The first four rows show the results of univariate regressions with only one

of the four betas as regressor. Consistent with Fama and French (1992), the first regression finds no significant relation between average return and beta. 
Interestingly, the relation between risk and return is partly restored when regular beta is replaced by semivariance beta. The cross-sectional premium on semi-variance beta is $2.4 \%$ (t-value 1.32) during this sample period. In the third and fourth regression we test ARM beta and downside covariance beta respectively and find lower premiums. As in our analysis of single-sorted portfolios, semivariance beta dominates the three other betas.

The last four rows show the results of multivariate regressions that include all other stock characteristics in addition to the betas. Including the other characteristics only strengthens the pattern. Most notably, the semivariance beta premium is $3.2 \%$ per annum ( $\mathrm{t}$-stat 2.32 ) and clearly dominates the risk premiums for the other betas. The coefficients of the other stock characteristics are consistent with what is documented elsewhere in the empirical literature. In sum, semivariance beta has a higher cross-sectional premium than the other betas.

\section{[Insert Table IV about here]}

\section{E. Alternative lower-partial moments}

Semi-variance is a special case of a general lower partial moment (LPM):

$$
\operatorname{LPM}(k, t) \equiv E\left[(R-k)^{t} \mid R \leq k\right]
$$

where $k$ is the return threshold and $t$ is the relevant order. The most common LPMs are expected loss $(t=1)$ and semi-variance $(t=2)$; other LPMs are less common. Related to this general downside risk measure is the following general LPM beta as a measure of systematic risk:

$$
\beta_{L P M(k, t), i} \equiv \frac{E\left[\left(R_{m}-k\right)^{t-1} R_{i} \mid R_{m} \leq k\right]}{E\left[\left(R_{m}-k\right)^{t-1} R_{m} \mid R_{m} \leq k\right]}
$$

We have thus far assumed that below-zero semi-variance $(t=2, k=0)$ is the relevant specification. Table $\mathrm{V}$ shows the results that are obtained if stocks are sorted based on alternative specifications.

The results generally are robust to the use of alternative values for the threshold; in order to significantly change the empirical results, we need to select a value from the left tail or the right tail of the distribution. A threshold from the left tail generally excludes too many return observations to allow for accurate 
estimation for downside beta. When the threshold is taken from the right tail, the LPMs seem increasingly less relevant as downside-risk measures.

The first-order LPM (expected loss) yields very similar results as semivariance, but the less common orders lead to deterioration and seem less relevant as downside risk measures for stocks. The threshold level gives similar results for values ranging between $-1 \%$ and $+3 \%$, including $33 \%$ and $69 \%$ of all observations respectively.

The results suggest that below-zero semi-variance is an appropriate downside risk measure for stocks and our results are reasonably robust for plausible changes in the relevant threshold and the relevant order.

\section{[Insert Table V about here]}

\section{F. Subsample results}

We have thus far analysed our full sample that covers 82 years of stock return history. It is well-known that the expected returns and risks evolve over time. This introduces the question whether our results are robust to the sample period under consideration. Table VI summarizes the results after splitting the full sample in to four subsamples of equal size.

The most striking result is that the mean spread is very high in the first subsample (1931-1949) and negative in the third subsample (1970 - 1988). It is beyond the scope of this paper to determine the origins of these variations; sampling error, temporary market inefficiencies, variations in risk attitude, or other factors. What is relevant for our study is that the semivariance beta in every subsample gives the highest mean spread. The second sub-sample overlaps with the sample of Jahankhani (1976) and for this particular sample period we find that regular beta and semi-variance beta give almost similar results, which confirms his earlier conclusions. These sub-sample results further support our conclusion that downside risk is relevant for stock investors and that systematic downside risk is best measured using the semivariance beta.

\section{[Insert Table VI about here]}

\section{Conclusions}

This study investigates the role of downside risk for the cross-section of US stock returns. The mean-semivariance equilibrium forwards the semivariance beta as the relevant measure of systematic downside risk for individual stocks. This beta 
generally differs systematically from two commonly employed alternative measures of systematic downside risk: the asymmetric response model (ARM) beta of Harlow and Rao (1989) and the downside-covariance beta used by Ang, Chen and Xing (2006). In contrast to the semivariance beta, these two alternative measures generally are not consistent with the first principles of choice theory.

To examine the empirical relevance of downside risk, we consider a broad cross-section of NYSE, AMEX and Nasdaq stocks and a long sample period including the important bear markets of the 1930s, 1970s and early 2000s. Using this sample, we form dynamic stock portfolios based on regular beta, the three downside betas, and other stock characteristics, including firm-level size, value and momentum. The average returns and betas of these portfolios are examined out-of-sample, to account for beta estimation error when predicting expected returns and betas.

Decile portfolios formed on semivariance beta yields an annual crosssectional mean spread of $5.5 \%$, compared to $3.7 \%$ for regular beta deciles. This result arises despite the fact that the semivariance beta is based on fewer return observations and is more difficult to estimate and predict than regular beta. Using the ARM regressions or covariance-based definition leads to markedly different results. The ARM results are very close to those obtained with the standard market beta and do not seem to reflect systematic downside risk. Using downside-covariance betas leads to more noisy estimates of systematic downside risk and a deterioration of the cross-sectional mean spread to $2.8 \%$.

Double-sorted portfolios help to further disentangle the effects of the various betas and control for the effect of other stock characteristics. Semivariance beta continues to yield a large and positive mean spread and beta spread even after correcting for regular beta, ARM beta and downside-covariance beta. However, after controlling for semivariance beta, the regular beta, ARM beta and downside-covariance beta cease to yield a positive mean spread. Semivariance beta continues to outperform the alternative measures of beta also after controlling for other stock characteristics, including firm-level size, value and momentum.

Our conclusions seem robust to the choice of the methodology, data set and definition of semi-variance. Using the multivariate regression approach of Fama and MacBeth (1973) yields similar conclusions as our analysis based on singlesorted and double-sorted portfolios. Semivariance beta dominates the other betas also in each of four historical subsamples and mostly so in most recent years. The results for semivariance beta are also robust to reasonable changes in the threshold that separates gains from losses. 
In summary, our results suggest that downside risk, when properly defined and estimated, is a driving force behind stock prices. Risk aversion thus not only helps to explain why stocks yield higher average returns than safer asset classes, but also why high-risk stocks yield higher average returns than low-risk stocks, ceteris paribus.

\section{References}

Ang, Andrew, Joseph Chen, and Yuhang Xing, 2006, "Downside Risk", Review of Financial Studies 19 (4), 1191-1239.

Artzner, Philippe, Freddy Delbaen, Jean-Marc Eber, and David Heath, 1999, "Coherent Measures of Risk", Mathematical Finance 9 (3), 203-228.

Bawa, Vijay, and Eric Lindenberg, 1977, "Capital Market Equilibrium in a Mean-Lower Partial Moment Framework”, Journal of Financial Economics 5 (2), 189-200.

Black, Fischer, Michael Jensen, and Myron Scholes, 1972, "The Capital Asset Pricing Model: Some Empirical Tests", Studies in the Theory of Capital Markets, Praeger, New York.

Fama, Eugene, and Kenneth French, 1992, "The Cross-Section of Expected Stock Returns", Journal of Finance 47 (2), 427-465.

Fama, Eugene, and Kenneth French, 1996, "Multifactor Explanations of Asset Pricing Anomalies", Journal of Finance 51 (1), 55-84.

Fama, Eugene, and James MacBeth, 1973, "Risk, Return, and Equilibrium: Empirical Tests", Journal of Political Economy 81 (3), 607-636.

Harlow, Van, and Ramesh Rao, 1989, "Asset Pricing in a Generalized Mean-Lower Partial Moment Framework: Theory and Evidence”, Journal of Financial and Quantitative Analysis 24 (3), 285-311.

Hogan, William, and James Warren, 1974, "Toward the Development of an Equilibrium CapitalMarket Model Based on Semivariance", Journal of Financial and Quantitative Analysis 9 (1), 111.

Jahankhani, Ali, 1976, "E-V and E-S Capital Asset Pricing Models: Some Empirical Tests", Journal of Financial and Quantitative Analysis, 11 (4), 513-528.

Markowitz, Harry, 1959, Portfolio Selection: Efficient Diversification of Investments, Wiley, New York. 
Price, Kelly, Barbara Price, and Timothy Nantell, 1982, "Variance and Lower Partial Moment Measures of Systematic Risk: Some Analytical and Empirical Results", Journal of Finance 37 (3), 843-855.

Reinganum, Marc, 1981, "A New Empirical Perspective on the CAPM", Journal of Financial and Quantitative Analysis 16 (4), 439-462. 
Table I: Single-Sorted Beta Portfolios

Common NYSE/AMEX/Nasdaq stocks are sorted into deciles each year at the end of December based on their (downside) betas. The sorts are constructed such that each portfolio contains an equal number of stocks at the formation date. The sample period is from January 1926 to December 2007 where the first 60 observations are used for estimating the stock betas, resulting in 924 monthly return observations for each portfolio. The table reports value weighted monthly mean excess returns of the decile portfolios and a portfolio that is long in the highest ranked decile and shorts the lowest ranked decile (H-L). Next to that, the standard deviation, skewness and kurtosis of the deciles' excess returns are reported. The final 4 rows show the different (downside) betas of the decile portfolios together with the H-L portfolio. The results are shown for regular beta, SV beta, ARM beta and DC beta in Panel A, B, C and D respectively.

\section{Panel A: Regular Beta}

\begin{tabular}{lccccccccccc} 
& Low & 2 & 3 & 4 & 5 & 6 & 7 & 8 & 9 & High & H-L \\
\hline Average & 0.60 & 0.60 & 0.70 & 0.70 & 0.84 & 0.76 & 0.79 & 0.78 & 0.85 & 0.91 & 0.31 \\
St.dev & 4.39 & 4.57 & 5.06 & 5.50 & 6.25 & 6.61 & 7.13 & 7.93 & 9.03 & 10.26 & \\
Skewness & 0.24 & 0.42 & 0.62 & 0.53 & 0.85 & 0.81 & 0.99 & 1.29 & 1.63 & 1.19 & \\
Kurtosis & 11.0 & 8.7 & 9.3 & 9.9 & 10.9 & 11.8 & 13.0 & 13.2 & 16.9 & 11.4 & \\
$\beta_{R e g}$ & 0.66 & 0.76 & 0.86 & 0.96 & 1.10 & 1.16 & 1.27 & 1.40 & 1.57 & 1.76 & 1.10 \\
$\beta_{S V}$ & 0.65 & 0.74 & 0.82 & 0.93 & 1.03 & 1.12 & 1.22 & 1.34 & 1.48 & 1.71 & 1.06 \\
$\beta_{A R M}$ & 0.64 & 0.73 & 0.82 & 0.92 & 1.03 & 1.10 & 1.19 & 1.30 & 1.45 & 1.66 & 1.02 \\
$\beta_{D C}$ & 0.76 & 0.78 & 0.84 & 0.96 & 1.04 & 1.11 & 1.21 & 1.31 & 1.43 & 1.66 & 0.89 \\
& & & & & & & & & & & \\
\hline
\end{tabular}

\section{Panel B: Semivariance Beta}

\begin{tabular}{lccccccccccc} 
& Low & 2 & 3 & 4 & 5 & 6 & 7 & 8 & 9 & High & H-L \\
\hline Average & 0.56 & 0.67 & 0.66 & 0.80 & 0.80 & 0.80 & 0.82 & 0.77 & 0.87 & 1.02 & 0.46 \\
St.dev & 4.46 & 4.69 & 5.08 & 5.76 & 6.56 & 6.87 & 7.46 & 8.17 & 9.56 & 10.66 & \\
Skewness & 0.04 & 0.31 & 0.05 & 1.00 & 0.81 & 1.61 & 1.32 & 1.37 & 1.92 & 1.36 & \\
Kurtosis & 9.0 & 7.4 & 7.1 & 12.7 & 11.5 & 17.7 & 15.4 & 15.6 & 20.2 & 11.7 & \\
$\beta_{R e g}$ & 0.70 & 0.80 & 0.89 & 1.02 & 1.17 & 1.20 & 1.33 & 1.43 & 1.66 & 1.78 & 1.07 \\
$\beta_{S V}$ & 0.71 & 0.77 & 0.87 & 0.93 & 1.11 & 1.09 & 1.23 & 1.36 & 1.52 & 1.68 & 0.98 \\
$\beta_{A R M}$ & 0.70 & 0.79 & 0.87 & 0.95 & 1.11 & 1.10 & 1.22 & 1.33 & 1.48 & 1.66 & 0.95 \\
$\beta_{D C}$ & 0.80 & 0.83 & 0.92 & 0.98 & 1.14 & 1.11 & 1.27 & 1.39 & 1.56 & 1.68 & 0.89 \\
& & & & & & & & & & & \\
\hline
\end{tabular}

Panel C: ARM Beta

\begin{tabular}{lccccccccccc} 
& Low & 2 & 3 & 4 & 5 & 6 & 7 & 8 & 9 & High & H-L \\
\hline Average & 0.58 & 0.60 & 0.63 & 0.76 & 0.81 & 0.83 & 0.77 & 0.79 & 0.77 & 0.91 & 0.33 \\
St.dev & 4.36 & 4.60 & 5.04 & 5.51 & 6.23 & 6.72 & 7.29 & 7.92 & 9.02 & 10.44 & \\
Skewness & 0.35 & 0.16 & 0.49 & 0.49 & 1.21 & 1.09 & 0.92 & 0.88 & 1.39 & 1.23 & \\
Kurtosis & 12.5 & 7.6 & 8.6 & 9.4 & 15.6 & 12.7 & 11.8 & 11.8 & 14.0 & 11.4 & \\
$\beta_{R e g}$ & 0.66 & 0.78 & 0.87 & 0.97 & 1.10 & 1.18 & 1.29 & 1.40 & 1.58 & 1.79 & 1.13 \\
$\beta_{S V}$ & 0.65 & 0.77 & 0.84 & 0.93 & 1.04 & 1.11 & 1.26 & 1.37 & 1.52 & 1.74 & 1.09 \\
$\beta_{A R M}$ & 0.63 & 0.75 & 0.83 & 0.92 & 1.03 & 1.11 & 1.22 & 1.33 & 1.47 & 1.68 & 1.05 \\
$\beta_{D C}$ & 0.75 & 0.82 & 0.87 & 0.95 & 1.05 & 1.09 & 1.24 & 1.37 & 1.48 & 1.69 & 0.94
\end{tabular}


Table I: (continued)

Panel D: Downside Covariance Beta

\begin{tabular}{lccccccccccc} 
& Low & 2 & 3 & 4 & 5 & 6 & 7 & 8 & 9 & High & H-L \\
\hline Average & 0.66 & 0.63 & 0.63 & 0.75 & 0.68 & 0.75 & 0.85 & 0.77 & 0.78 & 0.89 & 0.23 \\
St.dev & 4.98 & 4.71 & 5.08 & 5.47 & 5.50 & 6.45 & 6.89 & 7.53 & 8.21 & 9.70 & \\
Skewness & 0.48 & 0.26 & 0.35 & 0.33 & 0.17 & 1.22 & 1.28 & 1.45 & 0.92 & 1.31 & \\
Kurtosis & 11.6 & 8.6 & 9.1 & 8.0 & 6.0 & 13.7 & 15.1 & 17.4 & 10.8 & 12.4 & \\
$\beta_{\text {Reg }}$ & 0.82 & 0.81 & 0.89 & 0.98 & 0.98 & 1.14 & 1.22 & 1.33 & 1.44 & 1.64 & 0.82 \\
$\beta_{S V}$ & 0.81 & 0.81 & 0.87 & 0.96 & 0.98 & 1.08 & 1.15 & 1.27 & 1.42 & 1.59 & 0.78 \\
$\beta_{A R M}$ & 0.79 & 0.80 & 0.86 & 0.95 & 0.97 & 1.07 & 1.14 & 1.23 & 1.37 & 1.54 & 0.75 \\
$\beta_{D C}$ & 0.88 & 0.84 & 0.91 & 0.97 & 0.97 & 1.05 & 1.14 & 1.27 & 1.40 & 1.58 & 0.69
\end{tabular}




\section{Table II: Double-Sorted Beta Portfolios}

Double sorted portfolios are constructed each year in December by sorting on three measures of downside beta after controlling for regular beta (Panel A) and sorting on regular beta after controlling for one of the three downside beta measures SV, ARM and DC (in Panel B, Panel C and Panel D respectively). Common NYSE/AMEX/Nasdaq stocks are first sorted into quintiles using the control (downside) beta and next, within each quintile, sorted on the evaluated (downside) beta. The sorts are constructed such that each portfolio contains an equal number of stocks at the formation date. The sample period is from January 1926 to December 2007 where the first 60 observations are used for estimating the stock betas, resulting in 924 monthly return observations for each portfolio. The table reports value weighted monthly mean excess returns of the relevant (downside) beta portfolios averaged over the five control portfolios as well as the mean return spread (H-L). Next to that, the table reports the relevant (downside) betas of the quintiles together with the (downside) beta spread between the highest and lowest ranked portfolios.

Mean Excess Return

Beta

\begin{tabular}{|c|c|c|c|c|c|c|c|c|c|c|c|c|}
\hline \multicolumn{13}{|c|}{ Panel A: Controlled for Regular Beta } \\
\hline & Low & 2 & 3 & 4 & High & $\mathrm{H}-\mathrm{L}$ & Low & 2 & 3 & 4 & 5 & $\mathrm{H}-\mathrm{L}$ \\
\hline SV & 0.72 & 0.77 & 0.76 & 0.89 & 0.91 & 0.19 & 1.07 & 1.08 & 1.12 & 1.16 & 1.28 & 0.20 \\
\hline ARM & 0.75 & 0.73 & 0.77 & 0.80 & 0.82 & 0.07 & 1.01 & 1.08 & 1.11 & 1.17 & 1.28 & 0.27 \\
\hline $\mathrm{DC}$ & 0.75 & 0.76 & 0.78 & 0.76 & 0.81 & 0.07 & 1.09 & 1.09 & 1.14 & 1.12 & 1.23 & 0.15 \\
\hline
\end{tabular}

\begin{tabular}{|c|c|c|c|c|c|c|c|c|c|c|c|c|}
\hline \multicolumn{13}{|c|}{ Panel B: Controlled for Semivariance Beta } \\
\hline & Low & 2 & 3 & 4 & High & $\mathrm{H}-\mathrm{L}$ & Low & 2 & 3 & 4 & 5 & $\mathrm{H}-\mathrm{L}$ \\
\hline Regular & 0.81 & 0.85 & 0.80 & 0.82 & 0.76 & -0.05 & 1.05 & 1.12 & 1.19 & 1.22 & 1.37 & 0.31 \\
\hline ARM & 0.83 & 0.77 & 0.78 & 0.87 & 0.78 & -0.06 & 0.99 & 1.05 & 1.11 & 1.21 & 1.36 & 0.37 \\
\hline $\mathrm{DC}$ & 0.81 & 0.81 & 0.84 & 0.74 & 0.81 & 0.00 & 1.18 & 1.15 & 1.18 & 1.14 & 1.20 & 0.02 \\
\hline
\end{tabular}

\begin{tabular}{|c|c|c|c|c|c|c|c|c|c|c|c|c|}
\hline \multicolumn{13}{|c|}{ Panel C: Controlled for ARM Beta } \\
\hline & Low & 2 & 3 & 4 & High & $\mathrm{H}-\mathrm{L}$ & Low & 2 & 3 & 4 & 5 & $\mathrm{H}-\mathrm{L}$ \\
\hline Regular & 0.80 & 0.73 & 0.76 & 0.76 & 0.85 & 0.05 & 1.06 & 1.10 & 1.19 & 1.21 & 1.28 & 0.22 \\
\hline SV & 0.74 & 0.76 & 0.82 & 0.85 & 0.93 & 0.18 & 1.11 & 1.10 & 1.12 & 1.16 & 1.25 & 0.15 \\
\hline $\mathrm{DC}$ & 0.76 & 0.76 & 0.77 & 0.76 & 0.82 & 0.06 & 1.12 & 1.12 & 1.14 & 1.11 & 1.22 & 0.10 \\
\hline
\end{tabular}

\begin{tabular}{|c|c|c|c|c|c|c|c|c|c|c|c|c|}
\hline \multicolumn{13}{|c|}{ Panel D: Controlled for Downside-Covariance Beta } \\
\hline & Low & 2 & 3 & 4 & High & $\mathrm{H}-\mathrm{L}$ & Low & 2 & 3 & 4 & 5 & $\mathrm{H}-\mathrm{L}$ \\
\hline & 0.80 & 0.70 & 0.71 & 0.79 & 0.89 & 0.09 & 0.88 & 1.01 & 1.13 & 1.30 & 1.50 & 0.62 \\
\hline $\mathrm{SV}$ & 0.75 & 0.68 & 0.79 & 0.84 & 0.96 & 0.21 & 0.94 & 1.03 & 1.13 & 1.25 & 1.44 & 0.50 \\
\hline ARM & 0.78 & 0.64 & 0.77 & 0.83 & 0.88 & 0.10 & 0.86 & 1.00 & 1.10 & 1.25 & 1.46 & 0.61 \\
\hline
\end{tabular}


Table III: Controlling for Other Stock Characteristics

Double sorted portfolios are constructed each year in December by sorting on (downside) beta after controlling for size (Panel A), HML beta (Panel B), Momentum (Panel C), Reversal (Panel D), Variance (Panel E), Co-skewness (Panel F) Idiosyncratic Volatility (Panel G) and Industry (Panel H). Common NYSE/AMEX/Nasdaq stocks are first sorted into quintiles using the control variable and next, within each quintile, sorted on the relevant (downside) beta. The sorts are constructed such that each portfolio contains an equal number of stocks at the formation date except for the size quintiles for which NYSE breakpoints are used and the industry portfolios for which we use the 5-industry classification from Kenneth French's website. The HML factor is taken from the same website, momentum is based on past eleven month returns lagged one month, reversal is based on past 48 month returns lagged 12 months, variance and co-skewness are based on past 60 months and the idiosyncratic volatility is estimated using the Fama \& French (1993) three factor model on past 60 month returns. The sample period is from January 1926 to December 2007 where the first 60 observations are used for estimating the stock betas, resulting in 924 monthly return observations for each portfolio. The table reports value weighted monthly mean excess returns of the regular and SV beta portfolios averaged over the five control portfolios as well as the mean return spread (H-L). Next to that, the table reports the regular and SV betas of the quintiles together with the beta spread between the highest and lowest ranked portfolios.

Mean Excess Return

Beta

\begin{tabular}{llllllllllllll}
\hline & \multicolumn{10}{c}{ Panel A: Controlled for Size } \\
& Low & 2 & 3 & 4 & High & H-L & Low & 2 & 3 & 4 & 5 & H-L \\
\cline { 2 - 13 } Regular & 0.86 & 1.01 & 1.04 & 1.06 & 0.93 & 0.07 & & 0.82 & 1.07 & 1.23 & 1.44 & 1.65 & 0.84 \\
SV & 0.84 & 0.99 & 1.05 & 1.04 & 1.02 & 0.18 & & 0.80 & 0.98 & 1.15 & 1.31 & 1.54 & 0.73
\end{tabular}

\begin{tabular}{|c|c|c|c|c|c|c|c|c|c|c|c|c|}
\hline \multicolumn{13}{|c|}{ Panel B: Controlled for HML-Factor } \\
\hline & Low & 2 & 3 & 4 & High & H-L & Low & 2 & 3 & 4 & 5 & H-L \\
\hline \multirow{2}{*}{$\begin{array}{l}\text { Regular } \\
\text { SV }\end{array}$} & 0.70 & 0.72 & 0.81 & 0.89 & 0.91 & 0.20 & 0.83 & 0.98 & 1.14 & 1.33 & 1.59 & 0.76 \\
\hline & 0.67 & 0.75 & 0.87 & 0.92 & 0.96 & 0.29 & 0.84 & 0.97 & 1.09 & 1.28 & 1.52 & 0.68 \\
\hline \multicolumn{13}{|c|}{ Panel C: Controlled for Momentum } \\
\hline & Low & 2 & 3 & 4 & High & H-L & Low & 2 & 3 & 4 & 5 & H-L \\
\hline Regular & 0.66 & 0.74 & 0.75 & 0.74 & 0.67 & 0.02 & 0.87 & 1.03 & 1.19 & 1.34 & 1.57 & 0.70 \\
\hline SV & 0.64 & 0.67 & 0.74 & 0.81 & 0.79 & 0.15 & 0.87 & 1.01 & 1.15 & 1.29 & 1.54 & 0.66 \\
\hline
\end{tabular}

\begin{tabular}{|c|c|c|c|c|c|c|c|c|c|c|c|c|}
\hline \multicolumn{13}{|c|}{ Panel D: Controlled for Reversal } \\
\hline & Low & 2 & 3 & 4 & High & H-L & Low & 2 & 3 & 4 & 5 & $\mathrm{H}-\mathrm{L}$ \\
\hline Regular & 0.75 & 0.83 & 0.88 & 0.89 & 0.93 & 0.16 & 0.83 & 1.02 & 1.15 & 1.34 & 1.61 & 0.78 \\
\hline SV & 0.76 & 0.87 & 0.88 & 0.87 & 0.99 & 0.23 & 0.82 & 0.97 & 1.10 & 1.25 & 1.50 & 0.68 \\
\hline
\end{tabular}

\begin{tabular}{|c|c|c|c|c|c|c|c|c|c|c|c|c|}
\hline \multicolumn{13}{|c|}{ Panel E: Controlled for Variance } \\
\hline & Low & 2 & 3 & 4 & High & H-L & Low & 2 & 3 & 4 & 5 & H-L \\
\hline Regular & 0.77 & 0.86 & 0.80 & 0.84 & 0.78 & 0.00 & 1.01 & 1.12 & 1.24 & 1.32 & 1.43 & 0.43 \\
\hline SV & 0.73 & 0.80 & 0.83 & 0.87 & 0.86 & 0.14 & 1.09 & 1.15 & 1.25 & 1.30 & 1.41 & 0.32 \\
\hline
\end{tabular}

\begin{tabular}{|c|c|c|c|c|c|c|c|c|c|c|c|c|}
\hline \multicolumn{13}{|c|}{ Panel F: Controlled for Coskewness } \\
\hline & Low & 2 & 3 & 4 & High & H-L & Low & 2 & 3 & 4 & 5 & $\mathrm{H}-\mathrm{L}$ \\
\hline Regular & 0.73 & 0.78 & 0.82 & 0.78 & 0.89 & 0.16 & 0.86 & 1.00 & 1.17 & 1.29 & 1.54 & 0.68 \\
\hline SV & 0.69 & 0.79 & 0.79 & 0.82 & 0.97 & 0.28 & 0.87 & 1.01 & 1.13 & 1.26 & 1.50 & 0.63 \\
\hline
\end{tabular}

\begin{tabular}{|c|c|c|c|c|c|c|c|c|c|c|c|c|}
\hline \multicolumn{13}{|c|}{ Panel G: Controlled for Idiosyncratic Volatility } \\
\hline & Low & 2 & 3 & 4 & High & H-L & Low & 2 & 3 & 4 & 5 & $\mathrm{H}-\mathrm{L}$ \\
\hline Regular & 0.78 & 0.82 & 0.84 & 0.88 & 0.79 & 0.01 & 0.91 & 1.09 & 1.21 & 1.37 & 1.55 & 0.64 \\
\hline SV & 0.75 & 0.80 & 0.86 & 0.84 & 0.90 & 0.14 & 0.99 & 1.13 & 1.25 & 1.33 & 1.50 & 0.51 \\
\hline
\end{tabular}

\begin{tabular}{llllllllllllll}
\hline & \multicolumn{10}{c}{ Panel H: Controlled for Industry } \\
& Low & 2 & 3 & 4 & High & H-L & Low & 2 & 3 & 4 & 5 & H-L \\
\cline { 2 - 13 } Regular & 0.66 & 0.77 & 0.81 & 0.85 & 0.91 & 0.25 & 0.75 & 0.94 & 1.16 & 1.33 & 1.60 & 0.85 \\
SV & 0.67 & 0.77 & 0.89 & 0.75 & 1.03 & 0.37 & & 0.77 & 0.95 & 1.09 & 1.31 & 1.54 & 0.77
\end{tabular}




\section{Table IV Cross-Sectional Fama \& MacBeth Regressions}

We compute Fama \& MacBeth (1973) regressions of monthly excess returns of common NYSE/AMEX/Nasdaq stocks on individual firm characteristics. Cross-sectional regressions are run each month from January 1963 to December 2007 (540 months). For the univariate regressions I - IV (downside) beta is the independent variable. These (downside) betas are estimated using the past 60 month returns. In the multivariate regressions V - VIII we also include the firm's market capitalization (LnSize), the Book-toMarket ratio (BtM) defined as the book value of equity of previous calendar year's fiscal year-end divided by the market equity at the end of previous calendar year, past eleven month return lagged one month $\left(\mathrm{r}_{12-1}\right)$, past 48 month return lagged 12 months $\left(\mathrm{r}_{60-12}\right)$, standard deviation and coskewness which are both based on past 60 month returns. The reported coefficients are time-series averages of the monthly regression slopes multiplied by 100. The t-statistics of these averages are shown in brackets. The adjusted $\mathrm{R}^{2}$ of the regression model is reported underneath the regression number. All the independent variables are Winsorized each month at the $1 \%$ and $99 \%$ level.

\begin{tabular}{lrcccccccccc}
\hline & Const. & $\beta_{\text {Reg }}$ & $\beta_{S V}$ & $\beta_{A R M}$ & $\beta_{D C}$ & LnSize & BtM & $r_{12-1}$ & $r_{60-12}$ & Stdev & Cosk. \\
\hline I & 0.877 & -0.009 & & & & & & & & & \\
$1.9 \%$ & {$[6.61]$} & {$[-0.06]$} & & & & & & & & & \\
II & 0.641 & & 0.202 & & & & & & & & \\
$1.8 \%$ & {$[4.48]$} & & {$[1.32]$} & & & & & & & & \\
III & 0.851 & & & 0.023 & & & & & & & \\
$2.0 \%$ & {$[6.43]$} & & & {$[0.15]$} & & & & & & & \\
IV & 0.736 & & & & 0.115 & & & & & & \\
$1.1 \%$ & {$[4.33]$} & & & & {$[1.36]$} & & & & & & \\
V & 0.749 & 0.141 & & & & -0.132 & 0.195 & 0.472 & -0.156 & -0.968 & 0.005 \\
$6.1 \%$ & {$[5.50]$} & {$[1.31]$} & & & & {$[-4.96]$} & {$[3.64]$} & {$[2.87]$} & {$[-1.89]$} & {$[-0.58]$} & {$[0.20]$} \\
VI & 0.705 & & 0.266 & & & -0.140 & 0.191 & 0.556 & -0.079 & -1.056 & -0.040 \\
$6.1 \%$ & {$[5.19]$} & & {$[2.32]$} & & & {$[-5.22]$} & {$[3.56]$} & {$[3.20]$} & {$[-0.75]$} & {$[-0.62]$} & {$[-1.24]$} \\
VII & 0.750 & & & 0.200 & & -0.138 & 0.192 & 0.480 & -0.162 & -1.285 & -0.017 \\
$6.1 \%$ & {$[5.53]$} & & & {$[1.83]$} & & {$[-5.14]$} & {$[3.58]$} & {$[2.84]$} & {$[-1.81]$} & {$[-0.77]$} & {$[-0.65]$} \\
VIII & 0.745 & & & & 0.111 & -0.124 & 0.195 & 0.463 & -0.132 & -0.466 & -0.029 \\
$5.8 \%$ & {$[5.45]$} & & & & {$[1.84]$} & {$[-4.33]$} & {$[3.61]$} & {$[2.66]$} & {$[-1.36]$} & {$[-0.26]$} & {$[-0.88]$}
\end{tabular}


Table V: Alternative Lower-Partial Moments

Common NYSE/AMEX/Nasdaq stocks are sorted into deciles each year at the end of December based on their lower-partial moment betas using different orders $(t)$ and different thresholds $(k)$, ranging from $-5 \%$ up to $+5 \%$. The sorts are constructed such that each portfolio contains an equal number of stocks at the formation date. The sample period is from January 1926 to December 2007 where the first 60 observations are used for estimating the stock betas, resulting in 924 monthly value weighted return observations for each portfolio. The table reports the monthly return spread and the percentage of observations smaller or equal to the threshold $(k)$ in Panel A. The relevant lower-partial moment beta spread of the deciles are shown in Panel B.

\section{Panel A: Mean Return Spread}

Threshold $(k)$

\begin{tabular}{|c|c|c|c|c|c|c|c|c|c|c|c|c|}
\hline & & & & & & & & & & & \\
\hline & & $-5 \%$ & $-4 \%$ & $-3 \%$ & $-2 \%$ & $-1 \%$ & $0 \%$ & $1 \%$ & $2 \%$ & $3 \%$ & $4 \%$ & $5 \%$ \\
\hline \multirow{6}{*}{ 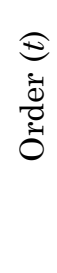 } & 0 & 0.31 & 0.29 & 0.54 & 0.30 & 0.27 & 0.02 & 0.02 & 0.07 & -0.14 & -0.04 & -0.08 \\
\hline & 1 & 0.31 & 0.43 & 0.51 & 0.53 & 0.38 & 0.37 & 0.39 & 0.48 & 0.55 & 0.59 & 0.44 \\
\hline & 2 & 0.32 & 0.28 & 0.26 & 0.36 & 0.46 & 0.46 & 0.45 & 0.49 & 0.44 & 0.42 & 0.34 \\
\hline & 3 & 0.25 & 0.23 & 0.19 & 0.19 & 0.24 & 0.29 & 0.30 & 0.31 & 0.39 & 0.42 & 0.47 \\
\hline & 4 & 0.27 & 0.21 & 0.22 & 0.15 & 0.17 & 0.19 & 0.25 & 0.26 & 0.29 & 0.30 & 0.33 \\
\hline & Obs. & $11 \%$ & $14 \%$ & $19 \%$ & $26 \%$ & $33 \%$ & $40 \%$ & $50 \%$ & $60 \%$ & $69 \%$ & $78 \%$ & $85 \%$ \\
\hline
\end{tabular}

Panel B: Beta Spread

\begin{tabular}{|c|c|c|c|c|c|c|c|c|c|c|c|c|}
\hline & \multicolumn{11}{|c|}{ Threshold $(k)$} \\
\hline & & $-5 \%$ & $-4 \%$ & $-3 \%$ & $-2 \%$ & $-1 \%$ & $0 \%$ & $1 \%$ & $2 \%$ & $3 \%$ & $4 \%$ & $5 \%$ \\
\hline \multirow{5}{*}{ 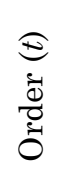 } & 0 & 0.92 & 1.50 & -0.21 & 0.13 & 1.01 & 0.09 & -2.47 & -1.20 & 0.20 & 0.19 & 0.39 \\
\hline & 1 & 0.98 & 0.87 & 0.88 & 0.87 & 0.96 & 0.93 & 0.81 & 0.75 & 0.54 & 0.61 & 0.84 \\
\hline & 2 & 0.82 & 0.87 & 0.92 & 0.94 & 0.96 & 0.98 & 0.99 & 1.00 & 0.98 & 0.94 & 0.91 \\
\hline & 3 & 0.63 & 0.71 & 0.74 & 0.79 & 0.82 & 0.85 & 0.87 & 0.90 & 0.91 & 0.92 & 0.91 \\
\hline & 4 & 0.58 & 0.59 & 0.63 & 0.66 & 0.69 & 0.73 & 0.75 & 0.79 & 0.82 & 0.83 & 0.85 \\
\hline
\end{tabular}


Table VI: Single-Sorted Beta Portfolios for Four Subsamples

Common NYSE/AMEX/Nasdaq stocks are sorted into deciles each year at the end of December based on their (downside) betas. The sorts are constructed such that each portfolio contains an equal number of stocks at the formation date. The sample periods are from January 1931 to December 1949 (Panel A), January 1950 to December 1969 (Panel B), January 1970 to December 1988 (Panel C) and January 1989 to December 2007 (Panel D). We use 60 monthly observations for estimating the stock betas (hence starting in January 1926). The table reports mean return spreads as well as the different (downside) beta spreads between the highest and the lowest ranked deciles.

Panel A: 1931 - 1949

High-Low Spread

\begin{tabular}{llrrrr} 
& Return & $\beta_{\text {Reg }}$ & $\beta_{S V}$ & $\beta_{A R M}$ & $\beta_{D C}$ \\
\hline Regular & 1.19 & 1.15 & 0.98 & 1.04 & 0.83 \\
SV & 1.29 & 1.23 & 1.03 & 1.11 & 0.83 \\
ARM & 1.24 & 1.17 & 1.00 & 1.07 & 0.86 \\
DC & 0.93 & 0.93 & 0.80 & 0.84 & 0.71 \\
& & & & & \\
\hline
\end{tabular}

Panel C: 1970 - 1988

High-Low Spread

\begin{tabular}{|c|c|c|c|c|c|}
\hline & Return & $\beta_{\text {Reg }}$ & $\beta_{S V}$ & $\beta_{A R M}$ & $\beta_{D C}$ \\
\hline Regular & -0.55 & 0.87 & 0.99 & 0.92 & 0.69 \\
\hline SV & -0.17 & 0.78 & 0.81 & 0.77 & 0.64 \\
\hline $\mathrm{ARI}$ & -0.31 & 0.98 & 1.07 & 1.03 & 0.80 \\
\hline $\mathrm{DC}$ & -0.44 & 0.54 & 0.61 & 0.55 & 0.41 \\
\hline
\end{tabular}

Panel B: 1950 - 1969

High-Low Spread

\begin{tabular}{|c|c|c|c|c|c|}
\hline & Return & $\beta_{\text {Reg }}$ & $\beta_{S V}$ & $\beta_{A R M}$ & $\beta_{D C}$ \\
\hline Regular & 0.34 & 0.85 & 0.95 & 0.77 & 1.01 \\
\hline SV & 0.33 & 0.71 & 0.73 & 0.62 & 0.75 \\
\hline $\mathrm{ARM}$ & 0.28 & 0.84 & 0.96 & 0.76 & 1.06 \\
\hline $\mathrm{DC}$ & 0.14 & 0.58 & 0.66 & 0.53 & 0.67 \\
\hline
\end{tabular}

Panel D: 1989 - 2007

High-Low Spread

\begin{tabular}{|c|c|c|c|c|c|}
\hline & Return & $\beta_{R e g}$ & $\beta_{S V}$ & $\beta_{A R M}$ & $\beta_{D C}$ \\
\hline Regular & 0.26 & 1.40 & 1.49 & 1.34 & 1.38 \\
\hline $\mathrm{SV}$ & 0.41 & 1.14 & 1.22 & 1.12 & 1.21 \\
\hline ARM & 0.12 & 1.35 & 1.47 & 1.30 & 1.33 \\
\hline $\mathrm{DC}$ & 0.30 & 1.03 & 1.08 & 0.99 & 1.00 \\
\hline
\end{tabular}




\section{Publications in the Report Series Research* in Management}

\section{ERIM Research Program: "Finance and Accounting"}

\section{9}

Sorting out Downside Beta

Thierry Post, Pim van Vliet, and Simon Lansdorp

ERS-2009-006-F\&A

http://hdl.handle.net/1765/14843

A complete overview of the ERIM Report Series Research in Management: https://ep.eur.nl/handle/1765/1

ERIM Research Programs:

LIS Business Processes, Logistics and Information Systems

ORG Organizing for Performance

MKT Marketing

F\&A Finance and Accounting

STR Strategy and Entrepreneurship 